\title{
Peaking of MMP-26 and TIMP-4 marks invasive transition in prostate cancer
}

\author{
Dangsheng $\mathrm{Li}^{1}$ \\ ${ }^{1}$ Cell Research, Shanghai Institutes for Biological Sciences, Chinese Academy of Sciences, 319 Yueyang Road, Shanghai 200031, \\ China
}

Cell Research (2006) 16:741. doi:10.1038/sj.cr.7310094; published online 14 Sep 2006

Prostate cancer is one of the leading health threats to man, and like many other cancers, early detection and treatment is crucial to improving the prognosis of patients. Progression of the disease from noninvasive high-grade prostatic intraepithelial neoplasia (HGPIN) to invasive adenocarcinoma is linked to the action of a group of proteolytic enzymes called matrix metalloproteinases (MMPs), which digest various components of the extracellular matrix and thus open ways for tumor metastasis. Previous studies have shown that one MMP, MMP-26, is expressed at a significantly higher level in human prostate carcinoma than in normal prostate tissues, and that it appears to play an important role in promoting invasion of prostate cancer cells [1]. In this issue of Cell Research, Lee et al. report detailed analyses of the expression pattern of MMP-26, along with its most potent endogenous inhibitor, TIMP-4 (TIMP stands for tissue inhibitor of metalloproteinases), in a number of prostate cancer samples derived from human patients [2]. Interestingly, they found that both MMP-26 and TIMP-4 exhibit the highest expression in HGPIN; and the levels of both proteins are significantly lower in adjacent cancer areas in the same tissues [2]. Consistent with earlier results, the lowest expression of MMP-26 (and TIMP-4) was found in non-neoplastic tissues. As HGPIN is considered the preinvasive precursor form of prostate cancer, the study by Lee et al. implicates that the expression of MMP-26 and TIMP-4 is coordinately regulated during disease progression. This finding is reminiscent of the authors' earlier study in breast cancer, where they showed that the expression of MMP-26 and TIMP-4 is significantly higher in preinvasive ductal carcinoma in situ comparing to invasive ductal carcinoma, hyperplasia, and normal breast epithelia [3]. While the functional significance of the apparently coordinated expression pattern of MMP-26 and TIMP-4 during malignant transition remains to be deciphered, these results suggest that peak expression of MMP-26 and TIMP-4 may underlie the conversion from noninvasive to invasive growth by the tumors. Moreover, the highest expression of these factors in HGPIN raises the possibility that they could be used as new biomarkers for early diagnosis of a subset of prostate cancer patients before metastasis.

\section{References}

1 Zhao YG, Xiao AZ, Newcomer RG, et al. Activation of pro-gelatinase B by endometase/matrilysin-2 promotes invasion of human prostate cancer cells. J Biol Chem 2003; 278:15056-15064.

2 Lee S, Desai KK, Iczkowski KA, et al. Coordinated peak expression of MMP-26 and TIMP-4 in preinvasive human prostate tumor. Cell Res 2006; 16:750-758.

3 Zhao YG, Xiao AZ, Park HI, et al. Endometase/matrilysin-2 in human breast ductal carcinoma in situ and its inhibition by tissue inhibitors of metalloproteinases-2 and -4: a putative role in the initiation of breast cancer invasion. Cancer Res 2004; 64:590-598. 